\title{
Investigation of First Flushes in a Small Rural-Agricultural Catchment
}

\author{
Xiao-lin Yang'*, Tai-kui Li ${ }^{2}$, Ke-ke Hua ${ }^{3}$, Yong-ling Zhang ${ }^{1 * * *}$ \\ 'Safety and Emergency Management Research Center, Henan Polytechnic University, Jiaozuo, 454000, China \\ ${ }^{2}$ Institute of Plant Nutrition, Resources and Environmental Science, \\ Henan Academy of Agricultural Sciences, Zhengzhou, 450002, China \\ ${ }^{3}$ Soil and Fertilizer Research Institute, Anhui Academy of Agricultural Sciences, \\ Hefei, 230000, China \\ Received: 7 March 2014 \\ Accepted: 3 August 2014
}

\begin{abstract}
The control of diffuse pollution requires information on the transport processes of those pollutants within a catchment. The characteristics of diffuse nitrogen and phosphorus discharged from a typical rural-agricultural catchment dominated by residential areas, sloping cropland, and forest land were monitored in the hilly area of the upper Yangtze River, China, and analyzed based on a total of eight rainfall-event runoff from August 2010 to September 2011. The results showed that the average of event mean concentrations (EMCs) of TN, DN, PN, TP, DP, and PP were 4.94, 3.18, 1.76, 1.11, 0.19, and $0.92 \mathrm{mg} / \mathrm{L}$, respectively. The high EMCs demonstrated diffuse pollution of rural-agricultural catchment posing great pressure on receiving water. The first flush phenomenon for nitrogen and phosphorus was identified in rural-agricultural catchment, especially for the medium and heavy rainfall events, and a total of $36 \%, 44 \%, 46 \%$, and $51 \%$ of the mass for TN, PN, TP, and PP, respectively, were discharged in the first $25 \%$ of the runoff. The first flush phenomenon suggested more attention should be paid on the management of the initial part of runoff in order to improve the efficiency of diffuse pollution control at catchment scale.
\end{abstract}

Keywords: diffuse pollution, first flush, nitrogen delivery, phosphorus delivery

\section{Introduction}

Diffuse pollution resulting from rainfall event runoff has been identified as one of the major causes of the deterioration of receiving waters [1]. However, diffuse pollution management was confined because it was difficult to understand the transport processes due to the high complexity of $\mathrm{N}$ and $\mathrm{P}$ cycles [2]. Therefore, in order to improve the effects of best management practices (BMPs) with lowest cost, the problems about how the pollutants are delivered and when the transport of pollutants are most intensive need to be understood deeply.

*e-mail: xiaolin4577@163.com

**e-mail: zhyongling@126.com (Corresponding Author)
To gain such understanding with respect to pollutant loading during rainfall events, the first flush of contaminants as an important practical phenomenon has been identified in previous urban runoff studies [3, 4], which suggested that a greater fraction of pollutant loading was contained in the initial part of the runoff volume. In practice, if a large portion of pollutant mass was delivered by the first portion of runoff, effective BMPs could be selected to treat the initial part of runoff (minimizing the amount of water, which has to be stored or diverted, and maximizing the mass of nutrients and pollutants not entering the downstream water body). Therefore, characterizing first flush phenomenon provides an important scientific basis for runoff manager to optimize treatment strategies [5]. 
The first flush phenomenon is frequently observed in the runoff of small, highly impervious areas, such as highways and parking lots [1, 3, 4]. However, relatively rare detailed research has been performed for rural-agricultural catchment with complex characteristics of both impervious and pervious land surfaces. Due to rapid development in rural areas and ecological migration as a result of the construction of the Three Gorges Reservoir (TGR), the ruralagricultural catchment has become an important catchment type in the hilly area of the upper Yangtze River, China. The diffuse pollution of rural-agricultural catchment posed a great pressure on the water quality of the TGR and the Yangtze River [6]. Therefore, understanding the delivery of pollutants during rainfall events and clarifying whether first flush phenomenon has occurred in rural-agricultural catchment are essential for water management of the Yangtze River.

The diffused pollution in rural-agricultural catchment was influenced by highly impervious and pervious land use. Therefore, we especially expect that a typical first flush phenomenon exists in these regions as in highly impervious areas that the most effective BMPs can be selected with the assistance of the knowledge of first flush achieving the objectives of minimizing the amount of water which has to be treated and maximizing the mass of nutrients or pollutants that do not enter the receiving water. Therefore, the primary objectives of this study are framed based on a fundamental question: when the transport of pollutants is most intensive during a rainfall event. The specific objectives of this work are as follows:

(1) Analyzing the relationship between the N, P transport and rainfall event.

(2) Whether the First flush of pollutants occurred.

(3) Determining the strength of first flush in rural-agricultural catchment.

\section{Methodologies}

\section{Study Site Description}

The water quality of the Yangtze River is greatly influenced by the nutrients discharged from the catchments of the upper Yangtze River, China [7]. This study was conducted in a typical rural-agricultural catchment (Jieliuyan catchment) located in the hilly area of the upper Yangtze River $\left(105^{\circ} 27^{\prime} \mathrm{E}, 31^{\circ} 16^{\prime} \mathrm{N}\right)$, China (Fig. 1). The study site has a moderate subtropical monsoon climate. During 19812008 , the area had an annual mean temperature of $17.3^{\circ} \mathrm{C}$ and a mean precipitation of $826 \mathrm{~mm}$. During the same period, $5.9 \%, 65.5 \%, 19.7 \%$, and $8.9 \%$ of the annual precipitation occurred in the spring (March to May), summer (June to August), autumn (September to November), and winter (December to February), respectively.

The Jieliuyan catchment (JC) has a drainage area of $0.35 \mathrm{~km}^{2}$ and elevation between 400 and $600 \mathrm{~m}$. The catchment consists of five main types of land use: sloping cropland $(42.0 \%)$, forestlands $(36.0 \%)$, paddy fields $(12.0 \%)$, and residential areas (3.5\%), and road (6.5\%) (Fig. 2).
The impervious land surface accounts for about $10.0 \%$ of total area of JC. Rice is planted in the lower parts of the valleys from May to September, with synthetic fertilizers applied at rates of $150 \mathrm{~kg} \mathrm{~N} / \mathrm{ha}, 90 \mathrm{~kg} \mathrm{P}_{2} \mathrm{O}_{5} / \mathrm{ha}$, and $36 \mathrm{~kg}$ $\mathrm{K}_{2} \mathrm{O} /$ ha. The rice crop is then rotated with rapeseed (Brassica campestris L.) from October to May, with synthetic fertilizers applied at rates of $130 \mathrm{~kg} \mathrm{~N} / \mathrm{ha}, 60 \mathrm{~kg}$ $\mathrm{P}_{2} \mathrm{O}_{5} / \mathrm{ha}$, and $36 \mathrm{~kg} \mathrm{~K} \mathrm{O} / \mathrm{ha}$. The sloping croplands in the upper parts of the catchment are planted conventionally with winter wheat (Triticum aestivum $\mathrm{L}$.) with synthetic fertilizers applied at rates of $130 \mathrm{~kg} \mathrm{~N} / \mathrm{ha}, 90 \mathrm{~kg} \mathrm{P}_{2} \mathrm{O}_{5} / \mathrm{ha}$, and $36 \mathrm{~kg} \mathrm{~K} 2 \mathrm{O} /$ ha in late October to May of the following year and then rotated with corn (Zea mays L.), with synthetic fertilizers applied at rates of $150 \mathrm{~kg} \mathrm{~N} / \mathrm{ha}, 90 \mathrm{~kg} \mathrm{P}_{2} \mathrm{O}_{5} / \mathrm{ha}$, and $36 \mathrm{~kg} \mathrm{~K}_{2} \mathrm{O} /$ ha from May to September.

\section{Sampling Strategy}

A total of 8 rainfall events were investigated at the monitoring station from August 2010 to September 2011 (Table 1).

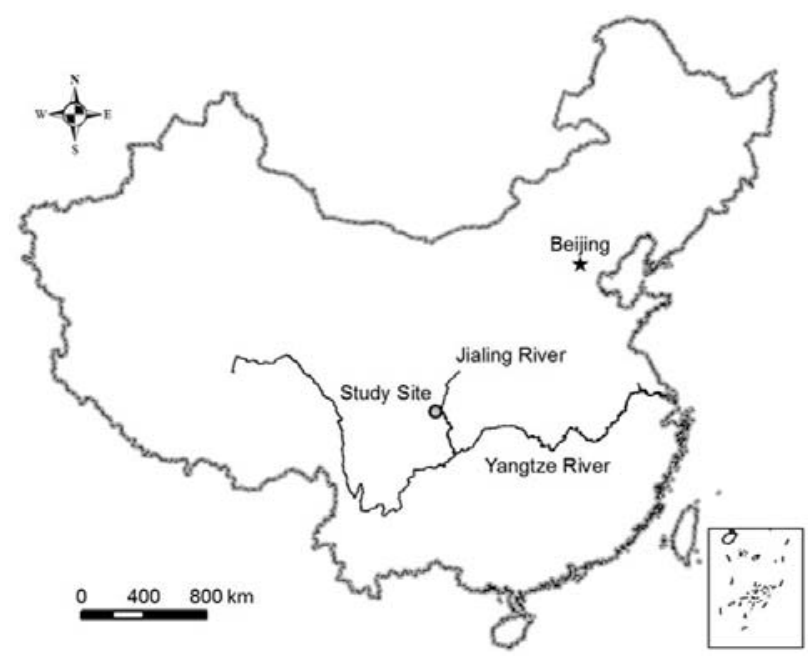

Fig. 1. Location of the study area in the hilly area of the Yangtze River.

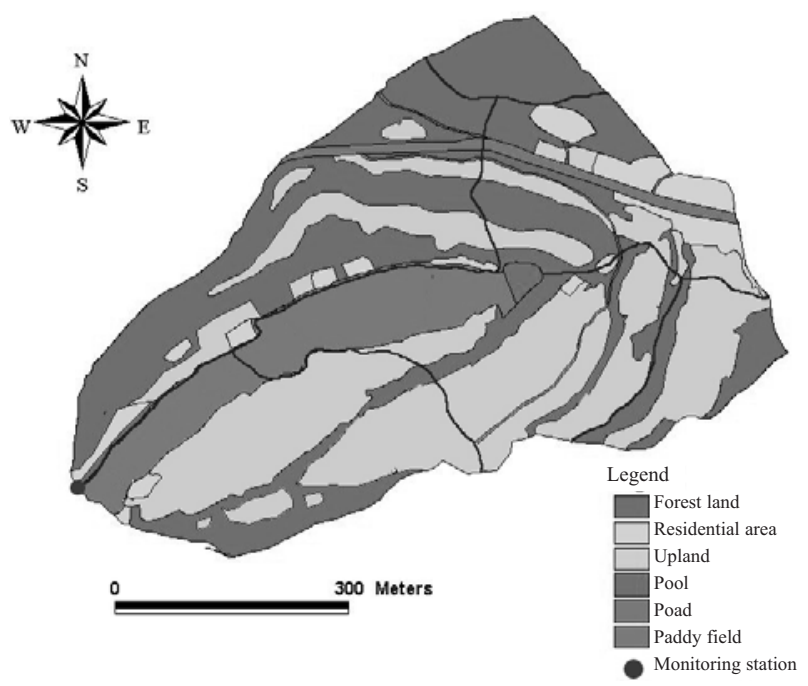

Fig. 2. The sketch of studied catchment-Jieliuyan catchment and the location of monitoring station. 
Table 1. Basic statistical characteristic of studied events in JC catchment.

\begin{tabular}{|c|c|c|c|c|c|}
\hline Events & $\begin{array}{l}\text { Precipitation } \\
\quad(\mathrm{mm})\end{array}$ & $\begin{array}{l}\text { Max. rainfall intensity } \\
\qquad(\mathrm{mm} / \mathrm{h})\end{array}$ & $\begin{array}{l}\text { Total flow volume } \\
\qquad\left(\mathrm{m}^{3}\right)\end{array}$ & $\begin{array}{l}\text { ADWP } \\
\text { (day) }\end{array}$ & Rainfall type \\
\hline $2010-07-15$ & 60.4 & 32.4 & 7025.7 & 1 & Heavy \\
\hline $2010-08-14$ & 6.5 & 5.2 & 554.23 & 14 & Small \\
\hline $2010-08-20$ & 15.8 & 10.8 & $2,094.966$ & 2 & Medium \\
\hline 2010-09-05 & 20.4 & 4.4 & 738.97 & 10 & Medium \\
\hline 2011-05-29 & 14.4 & 3.9 & $1,178.2$ & 7 & Medium \\
\hline 2011-06-21 & 79.7 & 24.6 & $7,043.3$ & 4 & Heavy \\
\hline $2011-06-26$ & 20.2 & 5.2 & $2,695.9$ & 3 & Medium \\
\hline 2011-09-07 & 32.5 & 8.4 & $2,303.9$ & 13 & Heavy \\
\hline
\end{tabular}

ADWP - antecedent dry weather period

Rainfall was monitored continuously using tipping bucket rain gauges (manufactured by Teledyne ISCO, Inc., USA) which were installed on the roof of the monitoring station. The runoff discharges were measured using V-notch weir installed at outlet, the automated water level recorders were set to read the real-time water levels. The water samples were collected with automatic samplers (ISCO 6712, manufactured by Teledyne ISCO, Inc., USA) which were triggered when the rainfall intensity was above $1 \mathrm{~mm} / \mathrm{h}$. Discrete samples were collected every 15 minutes during the first 3 hours of each event and every hour subsequently.

All samples were taken to the laboratory immediately and divided, preserved in a refrigerator with $4^{\circ} \mathrm{C}$ and analyzed within 24 hours. One portion of each sample was filtered through $0.45 \mu \mathrm{m}$ membrane filters and digested with $\mathrm{K}_{2} \mathrm{~S}_{2} \mathrm{O}_{7}$ solution for determination of dissolved nitrogen (DN) and dissolved phosphorus (DP). The unfiltered samples were digested with $\mathrm{K}_{2} \mathrm{~S}_{2} \mathrm{O}_{7}$ solution and analyzed for total nitrogen (TN) and total phosphorus (TP) following standard analytical methods [8]. The differences between the TN and TP and their respective dissolved forms were considered to be the particulate forms of $\mathrm{N}(\mathrm{PN})$ and $\mathrm{P}(\mathrm{PP})$ (e.g., $\mathrm{PN}=\mathrm{TN}-\mathrm{DN}$ and $\mathrm{PP}=\mathrm{TP}-\mathrm{DP}$ ) [9].

\section{Data Analysis}

\section{Event Mean Concentration}

The use of an event mean concentration (EMC) is appropriate for evaluating the effects of rainfall runoff on receiving waters [1]. The event mean concentration (EMC) represents a flow-weighted average concentration computed as total pollution mass divided by the total runoff volume for an event of duration [10].

$$
\mathrm{EMC}=\frac{M}{V}=\frac{\int_{t=t_{0}}^{t_{e}} C(t) Q(t) d t}{\int_{t=t_{0}}^{t_{e}} Q(t) d t}
$$

...where $M$ is the total mass of variables over the entire event duration $(\mathrm{g})$ and $V$ is the total volume of flow over the entire event duration $\left(\mathrm{m}^{3}\right)$.

\section{First Flush Quantification \\ $M(V)$}

One common method $[3,11]$ used to describe the hydrochemical changes over hydrograph is $M(V)$ curve, which was created by plotting normalized cumulative load (NCL) against normalized cumulative flow (NCF) as depicted in Fig. 3. The normalized cumulative load and the normalized cumulative flow can be calculated from the following equations:

$$
\mathrm{NCL}=\frac{\int_{t=t_{0}}^{t} C(t) Q(t) d t}{\int_{t=t_{0}}^{t} C(t) Q(t) d t} \text { and } \mathrm{NCF}=\frac{\int_{=t_{0}}^{t} Q(t) d t}{\int_{t=t_{0}}^{t_{e}} Q(t) d t}
$$

...where $C(t)$ is the nutrient concentration at time $t . Q(t)$ is the flow rate of the water; and $t_{0}$ and $t_{e}$ are the beginning and the end of the discharge processes, respectively.

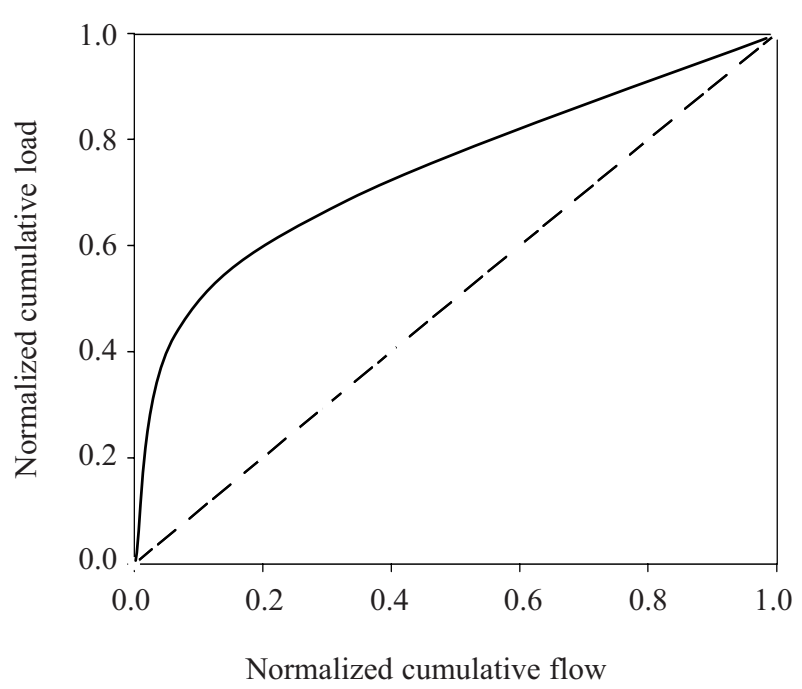

Fig. 3. The definition of $M(V)$ curve (A 1:1 line suggests that the pollutant mass and water volumes are proportional over the event. If the curve falls above the 1:1 line, a greater proportion of the load is concentrated in the initial part of the runoff volume. Conversely, a curve below the 1:1 line indicates that the nutrient loads arrive toward the end of the event.) 
$\mathbf{F F}_{25}$

The parameter $\mathrm{FF}_{25}$ represents the percentage of total mass delivered in the first $25 \%$ of runoff and was used frequently to identify the significance of a first flush [10]. For example, if the $\mathrm{FF}_{25}$ is equal to 0.50 , this means that $50 \%$ of this pollutant is transported in the first $25 \%$ of the runoff, significant "first flush" is identified.

\section{Results and Discussion}

\section{Hydrological Processes}

A total of eight rain events were investigated at the monitoring site. The basic rainfall characteristics are presented in Table 1. The rainfall for each event ranged from 6.5 to $79.7 \mathrm{~mm}$, and the maximal rainfall intensity for each event ranged from 3.9 to $32.4 \mathrm{~mm} / \mathrm{h}$. Statistical analysis showed that precipitation was significantly correlated with runoff discharges $\left(\mathrm{Y}_{\text {ruonff }}=97.4 \mathrm{X}_{\text {precipitation }}-88.1, \mathrm{n}=8\right.$; $\left.\mathrm{R}^{2}=0.89\right)$. In this study, the events on $2010-8-14,2010-8$ 20, and 2011-9-7 represent small $(6.5 \mathrm{~mm})$, medium (15.8 $\mathrm{mm})$, and heavy rainfall $(32.5 \mathrm{~mm})$ events, respectively, and were selected as representative examples in the description of the hydrological and hydro-chemical process below.

Fig. 4 presents the hydrological process of the three types of rainfall events in the catchment. The delayed runoff generation was observed at the outlets, and the peak discharge occurred approximately one hour after the peak rainfall. Meanwhile, the runoff events had slow flow recessions and smoothly discharged peaks. The hydrological response processes were deeply different with the results observed in the area dominated by impervious land surface in which the runoff was generally observed immediately when the measurable rain began, and the flow velocities corresponded closely to rainfall intensity. The runoff falling limbs were very short, and the flow velocity decreased immediately when the rain stopped $[6,12]$.
The differences of hydrological processes seem to be related to the characteristics of land surface. In the previous studies $[6,12]$, as a result of the higher percentage of impervious area, the surface runoff generated almost immediately at the beginning of the rainfall events, and reached the monitoring site in a short time. In contrast, due to the canopy modifications the amount and intensity of rainfall that reach the soil surface [13] and the surface soil properties regulating the hydrological flow paths [14], the subsurface runoff generally contributes a substantial fraction of runoff monitored in the catchment with high-permeability soil and a high percentage of vegetation coverage. Therefore, the delayed runoff generation and slower flow recession were observed at the outlet of JC due to the high percentage of the pervious area [15].

\section{N, P Concentrations during Rainfall Events}

\section{Temporal Variation of N, P Concentrations at Single Events}

At present study, the concentration of TN, DN, and PN ranged from 1.3 to $12.6 \mathrm{mg} / \mathrm{L}, 0.9$ to $6.0 \mathrm{mg} / \mathrm{L}, 0.2$ to 10.1 $\mathrm{mg} / \mathrm{L}$, respectively, for three typical rainfall events (Fig. 5a). During the small rainfall event on 2010-8-14, a smaller variation of nitrogen concentration was observed, the concentration of TN ranged from 1.5 to $2.8 \mathrm{mg} / \mathrm{L}$, and DN was the dominant form of $\mathrm{N}$ at the total duration of the event, which ranged from 1.3 to $2.0 \mathrm{mg} / \mathrm{L}$. However, during the medium and heavy rainfall events of 2010-8-20 and 2011-9-7, great variations of nitrogen concentration were observed, and PN was the dominant form of $\mathrm{N}$ at the early stage of the rainfall events, followed by DN as the dominant form at the subsequent stage. The concentrations of $\mathrm{TN}$ and PN were very high in the early stage of the rainfall events, especially for the first 3 hours of events duration, followed by a rapid decrease. In contrast, the concentrations of DN showed a relatively slight change throughout the course of the rainfall events.
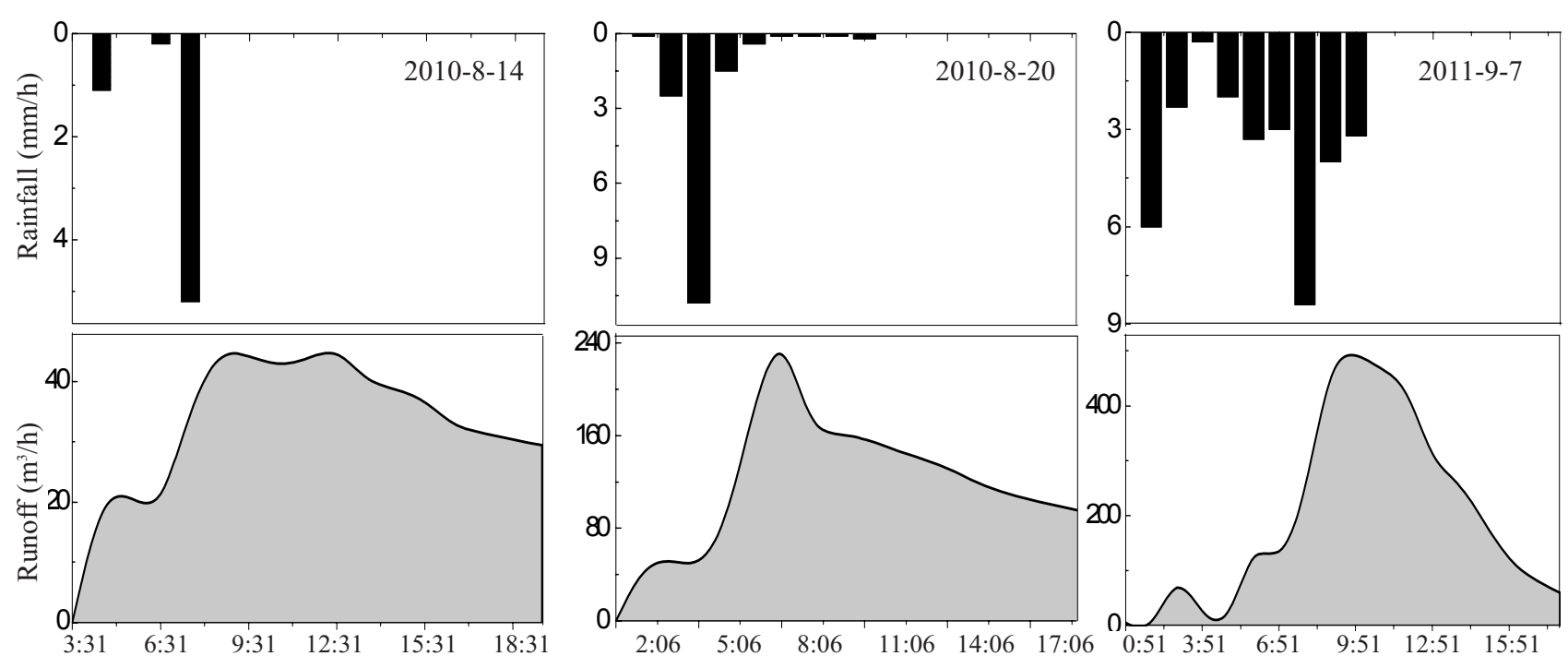

Fig. 4. Hydrological process of the rainfall events on 2010-8-14, 2010-8-20, and 2011-9-7 for JC. (JC represents Jieliuyan catchment). 
For three typical rainfall events, the concentrations of TP, DP, and PP ranged from 0.1 to $6.3 \mathrm{mg} / \mathrm{L}, 0.02$ to 0.9 $\mathrm{mg} / \mathrm{L}$, and 0.1 to $5.9 \mathrm{mg} / \mathrm{L}$, respectively, and obvious peak concentrations were observed for TP and PP in the initial period of the rainfall events. For example, the peak concentrations of TP were $0.4,1.3$, and $6.3 \mathrm{mg} / \mathrm{L}$ for events of 2010-8-14, 2010-8-20, and 2011-9-7, respectively, and identified in the first 3 hours of the duration of events. Conversely, the DP concentration showed slight changes during a single rain event for the three typical events (Fig. 5b).

The result of this study indicated that transport process of nitrogen and phosphorus vary considerably from event to event, and in general rainfall size seems to be the most
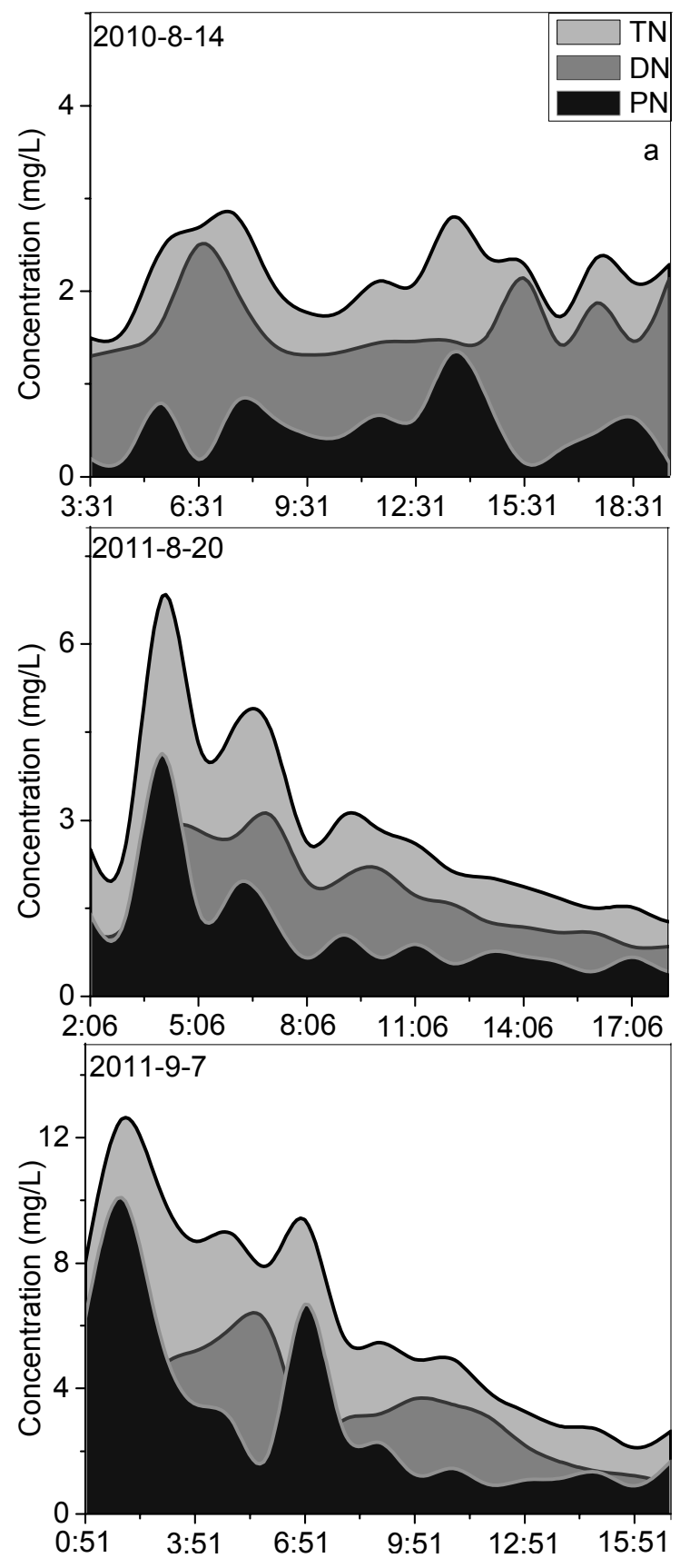

important factor influencing the transport process, and the significant preceding increase in nutrient concentrations and peak distribution of loads in the initial period of an event within the investigated catchment occurred in medium and heavy events (Figs. 5a and b). Such a phenomenon was also observed elsewhere $[9,16]$.

The preceding increase of the nutrient concentration was generally observed in the storm runoff from urban area, park, and so on, which was dominated by a high percentage of impervious area $[1,6]$. In this study, such preceding increases also were observed for the rural-agricultural catchment in the hilly area of the upper Yangtze River. The phenomenon that the preceding increase in the nutrient concentrations and peak distribution of loads in the initial peri-
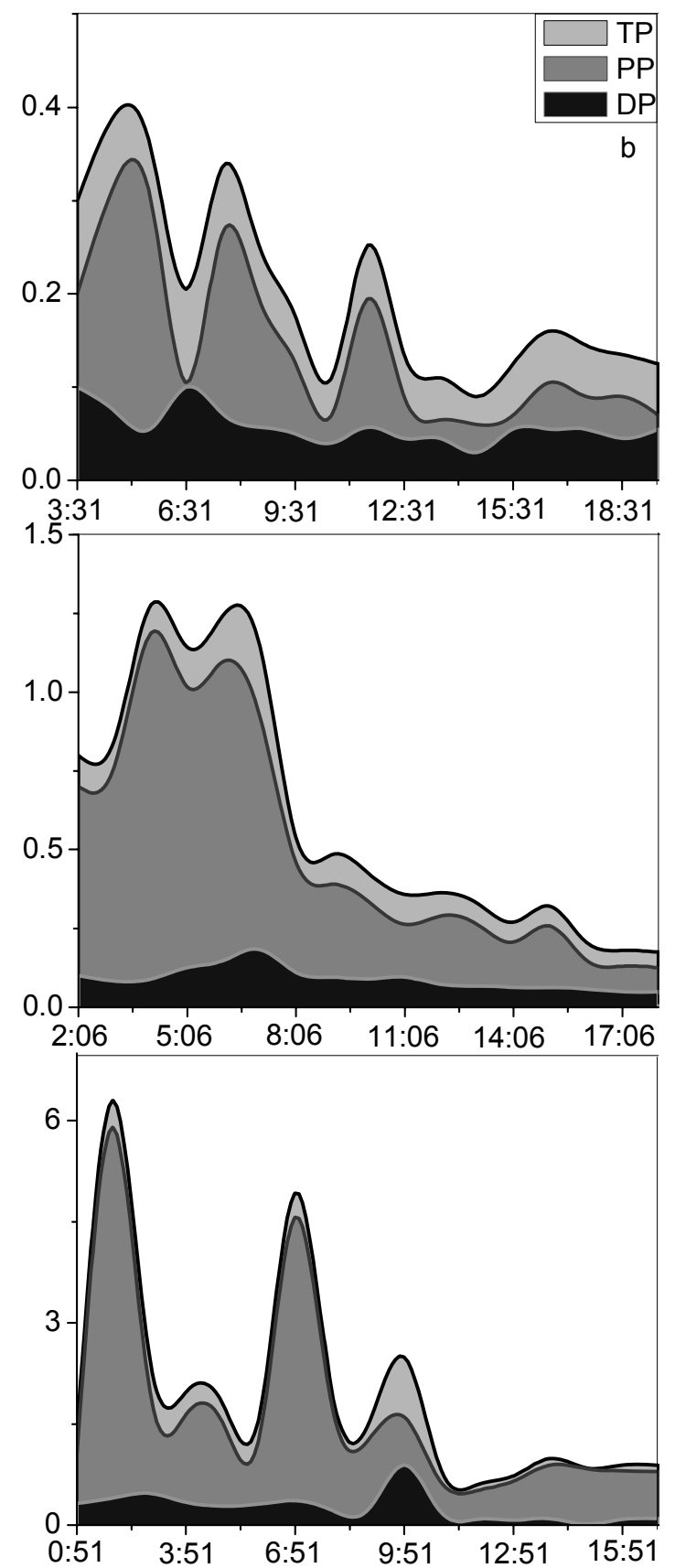

Fig. 5. Pollutogragphs of rainfall events at 2010-08-14, 2010-08-20, and 2011-09-07 for Jieliuyan Catchment (a - nitrogen; b - phosphorus). 
Table 2. Variations of EMCs in nitrogen and phosphorus for eight rainfall events in rural-agricultural catchment for different rainfall types.

\begin{tabular}{|c|c|c|c|c|c|c|}
\hline \multirow{2}{*}{ Rainfall type } & \multicolumn{6}{|c|}{ Concentration(mg/L) } \\
\hline & $\mathrm{TN}$ & DN & $\mathrm{PN}$ & $\mathrm{TP}$ & DP & PP \\
\hline Small events $(\mathrm{N}=1)$ & 2.33 & 1.63 & 0.71 & 0.51 & 0.12 & 0.38 \\
\hline Medium events $(\mathrm{N}=4)$ & $4.43 \pm 1.64$ & $2.91 \pm 1.01$ & $1.52 \pm 0.65$ & $0.84 \pm 0.29$ & $0.18 \pm 0.07$ & $0.67 \pm 0.28$ \\
\hline Heavy events $(\mathrm{N}=3)$ & $6.48 \pm 0.97$ & $4.06 \pm 0.31$ & $2.42 \pm 0.79$ & $1.67 \pm 0.74$ & $0.22 \pm 0.08$ & $1.45 \pm 0.67$ \\
\hline Mean $(\mathrm{N}=8)$ & $4.94 \pm 1.88$ & $3.18 \pm 1.08$ & $1.76 \pm 0.85$ & $1.11 \pm 0.65$ & $0.19 \pm 0.60$ & $0.92 \pm 0.60$ \\
\hline
\end{tabular}

od of an event was called "first flush" was proposed by Vorreiter and Hickey [17] first, which provided important information for defining the crucial time at which the nutrients are transported [3-5]. In this study, a significantly concentrated transport regime was found for TN, TP, PN, AN, and $\mathrm{PP}$ in the typical rural-agricultural catchment, especially in medium and heavy events. Therefore, the diffuse pollution in rural-agricultural catchment can be reduced dramatically by implementing infiltration or sedimentation measures to remove a greater fraction of the pollution load in the initial part of the runoff.

\section{Event Mean Concentration}

In our investigation the average of EMCs of TN, DN, $\mathrm{PN}, \mathrm{TP}, \mathrm{DP}$, and PP during the 8 rainfall events were $4.94 \pm 1.88 \mathrm{mg} / \mathrm{L}, 3.18 \pm 1.08 \mathrm{mg} / \mathrm{L}, \quad 1.76 \pm 0.85 \mathrm{mg} / \mathrm{L}$, $1.11 \pm 0.65 \mathrm{mg} / \mathrm{L}, 0.19 \pm 0.60 \mathrm{mg} / \mathrm{L}$, and $0.92 \pm 0.60 \mathrm{mg} / \mathrm{L}$, respectively (Table 2). The values of EMC for nitrogen and phosphorus also vary from event to event, and in generally rainfall size. For example, in the present study, the EMCs of $\mathrm{TN}$ and TP are $2.33 \mathrm{mg} / \mathrm{L}, 0.51 \mathrm{mg} / \mathrm{L}$ for a small rainfall event, and $4.43 \mathrm{mg} / \mathrm{L}, 0.84 \mathrm{mg} / \mathrm{L}$ and $6.48 \mathrm{mg} / \mathrm{L}, 1.67 \mathrm{mg} / \mathrm{L}$ for medium and heavy rainfall events, respectively (Table 2). This phenomenon implies that the greatest amount of nutrient export within the investigated catchment occurred in heavy and storm events, and more attention needs to be given to the control of diffuse pollution from rural-agricultural catchment during medium and heavy rainfall events. This phenomenon was consistent with the results of other research $[18,19]$.

In previous studies, agricultural activities, particularly the on-farm use of agrochemicals, have always been recognized as important sources of surface and subsurface water contamination in a catchment, and attention is generally focused on the movement of nutrients from agricultural fields [20]. For example, losses of nitrogen and phosphorus from eight small (85-2830 ha) agricultural catchments in Norway were analyzed by Bechmann et al. [21], the average event mean concentrations of TN and TP varied from 1.1 to $11.2 \mathrm{mg} / \mathrm{L}$, and 0.06 to $0.42 \mathrm{mg} / \mathrm{L}$, respectively. Tang et al. [22] found event mean concentrations of TN and TP of $2.0 \mathrm{mg} / \mathrm{L}$ and $0.1 \mathrm{mg} / \mathrm{L}$, respectively, in stormwater runoff, in a typical agricultural catchment in China. Mckergow et al. [23] reported that the average TN EMC value of an agricultural area was 2.51-3.26 mg/L.
The urbanized area is a unique environment with characteristic disturbance gradients that alter natural biogeochemical cycles [24-26]. Human activities control major factors driving these cycles, including land use change and soil variability, atmospheric chemistry, and hydrologic modifications [26]. Nitrogen $(\mathrm{N})$ and phosphorus $(\mathrm{P})$ are derived from multiple sources and pathways in urbanized watersheds and thus water runoff is a major contributor to river pollution in many areas $[27,28]$. For example, Lee et al. [1] reported that the mean TN EMC concentration of residential catchments ranged from 1.4-13.8 $\mathrm{mg} / \mathrm{L}$. Brezonik and Stadelmann [29] reported that the mean EMC of TN and TP were 3.08 and $0.59 \mathrm{mg} / \mathrm{L}$, respectively, in the Twin Cities metropolitan area, Minnesota, USA.

The mean EMC of TN and TP in the present study in the hilly area of the upper Yangtze River Basin, China, were $4.94 \pm 1.88 \mathrm{mg} / \mathrm{L}$ and $1.11 \pm 0.65 \mathrm{mg} / \mathrm{L}$, respectively, and were higher than the reported values, indicating that the impact of nutrient concentrations from the rural-agricultural catchment on receiving water were high. Furthermore, the results suggest that the concentrations of nitrogen and phosphorus in rainfall runoff were much higher than the thresholds of eutrophication by international standards $(0.2 \mathrm{mg} / \mathrm{L}$ for $\mathrm{TN}$, $0.02 \mathrm{mg} / \mathrm{L}$ for TP) proposed first by Thomann [30], and the average EMCs for TN and TP were approximately 22.5 and 35.0 times higher than the thresholds, which imply the ruralagricultural catchment is a potential "high-risk" discharger and posed a great pressure on the downstream water quality in the hilly area of the upper Yangtze River.

\section{Analysis of First Flush}

$M(V)$ curves of normalized cumulative loads for different nutrient species against normalized cumulative flow were presented in Fig. 6 . The results showed that the $M(V)$ curves of TN, PN, TP, and PP were all clearly located above the 1:1 line during the rainfall events of 2010-8-20 and 2011-9-7 which represent medium and heavy rain, respectively. However, only the $M(V)$ curves for TP and PP were distributed above the 1:1 line for the event of 2010-8-14 which represent of small event, and the $M(V)$ curves for other nutrient species appeared close to the 1:1 line curves. These results indicated that a larger proportion of the mass for nitrogen and phosphorus was transported in the initial stage of runoff during the medium and heavy rainfall events, and only for phosphorus during the small rainfall event. 
The preceding increase in concentrations and the location of $M(V)$ curves for TP, PP, TN, and PN indicated the occurrence of first flush, to quantify the strength of the First flush effects of the different forms of nutrient transport in JC catchment, the $\mathrm{FF}_{25}$ parameter [16] was employed. In this study, the average values of $\mathrm{FF}_{25}$ for eight studied events were 0.36 for TN, for $0.31 \mathrm{DN}, 0.44$ for PN, 0.46 for TP, 0.28 for DP, and 0.51 for PP (Fig. 7). This means that a total of $36 \%, 31 \%, 44 \%, 46 \%, 28 \%$ and $51 \%$ of the mass for TN, DN, PN, TP, DP, and PP, respectively, were discharged in the first $25 \%$ of the runoff. These results indicate
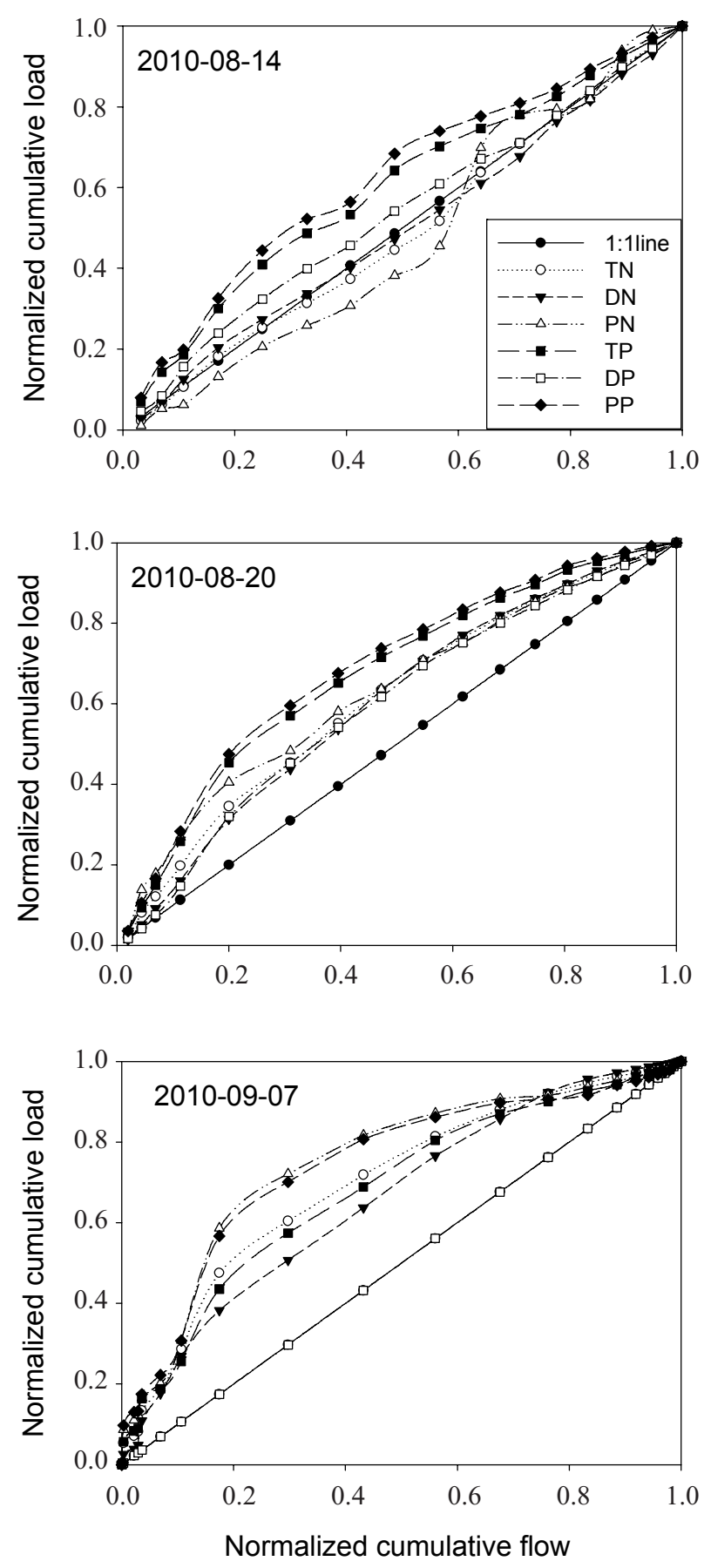

Fig. 6. NCL-plots of 2010-08-14, 2010-08-20, and 2011-09-07 for JC normalized cumulative load against normalized cumulative discharge.

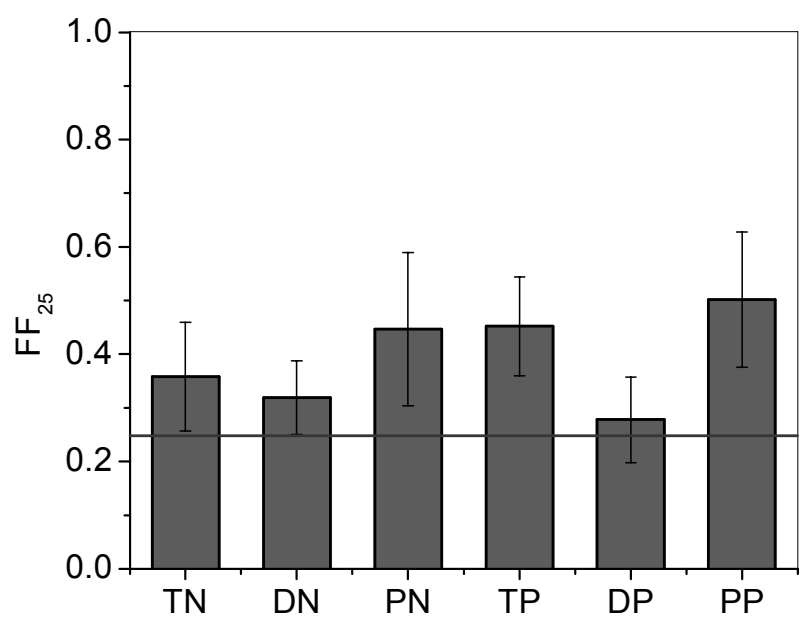

Fig. 7. The $\mathrm{FF}_{25} \mathrm{~S}$ of different species were calculated for a total of eight rainfall events at Jieliuyan catchment sites.

that the significant first flush effects occurred for TN, TP, $\mathrm{PN}$, and PP, and the magnitude of the first flush was in the order of $\mathrm{PP}>\mathrm{TP}>\mathrm{PN}>\mathrm{TN}$.

In general, the first flush phenomenon has been frequently observed in small rural or urban catchments with a large portion of impervious area in which surface flow regime dominated the runoff process $[1,3,4,9]$. The results of this study indicated that the First flush phenomenon was also identified in a typical rural-agricultural catchment and the concentrated losing process will provide an important scientific basis for the management of diffuse pollution in the rural-agricultural in the hilly area of the upper Yangtze River.

\section{BMP Selection}

The analysis of EMC indicated that the rural-agricultural catchment posed a great pressure on the downstream water quality, therefore more attention should be paid on the diffuse pollution from rural-agricultural catchment. Furthermore, our findings suggest a significantly concentrated transport regime for total $\mathrm{N}$ and $\mathrm{P}$ and particulate $\mathrm{N}$ and $\mathrm{P}$ at rural-agricultural catchment, which demonstrated an obvious strength of first flush, the highest value of $\mathrm{FF}_{25}$ for eight rainfall events was calculated for PN (0.69), followed by PP (0.57), TN (0.56), and TP (0.51). This means that $69 \%, 57 \%, 56 \%$, and $51 \%$ of the mass for PN, PP, TN, $\mathrm{TP}$, respectively, were discharged in the first $25 \%$ of the runoff. Therefore, these results suggesting that pollutants are transported is most intensive in the initial period of runoff duration, for example the first 3 hours, and applying treatment BMPs (e.g. wastewater infiltration measures, direct pumping of wastewater into detention ponds) in the early part of runoff could remove the diffuse pollutants more effectively than randomly timed BMPs.

\section{Conclusions}

In this study, the average EMCs of TN and TP for all investigated rainfall events were approximately $4.94 \pm 1.88$ 
$\mathrm{mg} / \mathrm{L}$ and $1.11 \pm 0.65 \mathrm{mg} / \mathrm{L}$, the analysis of EMCs of nitrogen and phosphorus indicated that the rainfall runoff from the rural-agricultural catchment in the hilly area of the upper Yangtze River, China, was severely polluted based on the thresholds of eutrophication by international standards. The preceding increase in the nutrient concentrations and peak distribution of loads in the initial period of an event indicated the first three hours was the crucial time at which the nutrients are transported intensively. Furthermore, the average values of $\mathrm{FF}_{25}$ indicated a total of $36 \%, 31 \%, 44 \%, 46 \%, 28 \%$, and $51 \%$ of the mass for $\mathrm{TN}$, DN, PN, TP, DP, and PP, respectively, were discharged in the first $25 \%$ of the runoff. The important first flush phenomenon has been investigated in rural-agricultural catchment, especially for nutrient transport during the medium and heavy rainfall events. Thus greater attention needs to be given to the ever-increasing rural-agricultural catchments in the hilly area of upper Yangtze River for the management of diffuse pollution, and best management practice, such as infiltration or sedimentation measures, should be employed to control the nutrient loss in the initial period of rainfall events.

In view of the large temporal variations of $\mathrm{N}$ and $\mathrm{P}$ concentration during single rainfall events in rural-agricultural catchment, a more intensive sampling program is recommended, especially in the initial period of runoff process during the medium and heavy rainfall events.

\section{Acknowledgements}

Funding for this project was provided by the Natural Science Foundation of China (Grant No. 41271321 and 41001119) and the National key Basic Research Program of China (Grant No. 2012CB417101). We also would like to thank Youcai Luo, Xunqiang Cheng, and Qiuxia Tan for their assistance in sample collection and analysis.

\section{References}

1. LEE J.H., BANG K.W., KETCHUM L.H., CHOE J.S., YU M.J. First flush analysis of urban storm runoff. Sci. Total Environ. 293, 163, 2002.

2. WICKHAM J.D., JONES K.B., WADE T.G., RIITTERS K.H. Uncertainty in scaling nutrient export coefficients. In: Wu, K., Li, H., Loucks, OL.(Eds.).Scaling and uncertainty analysis in ecology. Springer, New York (Chapter12), 2006.

3. MA M, KHAN S, LI S, KIM LH. First flush phenomena for highways: how it can be meaningfully defined. Proceedings of nineth International Conference on Urban Drainage, September, Portlnad, Oregon, 2002.

4. SANSALONE J.J., CRISTINA C.M. First flush concepts for suspended and dissolved solids in small impervious watersheds. Journal of environmental engineering 130, (11), 1301, 2004.

5. KANGA J.H., KAYHANIANB M., STENSTROM M.K. Implications of a kinematic wave model for first flush treatment design. Water research 40, 3820, 2006.
6. LUO Z.X., ZHU B., WANG T., ZHANG J., XIN W., WANG D. Characterization of rainfall-runoff pollution in a small rural township in a hilly area with purple soil. Acta scientiae circumstantiae 28, (9), 1823, 2008.

7. ZHU B., WANG Z.H., ZHANG X.B. Phosphorus fractions and release potential of ditch sediments from different land uses in a small catchment of the upper Yangtze River. Journal of Soils Sediments 12, 27890, 2012.

8. EBINA J., TSUTSUI T., SHIRAI T. Simultaneous determination of total nitrogen and phosphorus in water using peroxodisulfate oxidation. Water Res. 17, 1721, 1983.

9. STUTTER M.I., LANGAN S.J., COOPER R.J. Spatial and temporal dynamics of stream water particualte and dissolved N, P and C forms along a catchment transect, NE Scotland. J. Hydrol. 50, 187, 2008.

10. OBERMANN M., ROSENWINKEL K.H., TOURNOUD G.M. Investigation of first flushes in a medium-sized Mediterranean watershed. J. Hydrol. 373, 405, 2009.

11. HATHAWAY J.M., HUNT W.F. Evaluation of first flush for indicator bacteria and total suspended solids in urban stormwater runoff. Water Air Soil Poll. 217, 135, 2011.

12. YANG X.L., CHEN Z.C., ZHU B. Transport characteristics of nitrogen on different land uses patterns in the hilly area of purple soil. Journal of Soil and Water Conservation 2, 71, 2013.

13. PUIGDEFABREGAS J. The role of vegetation patterns in structuring runoff and sediment fluxes in drylands. Earth Surface Processes and Landforms 30, (2), 133, 2005.

14. ARNAU-ROSALEN E., CALVO-CASES A., BOIXFAYOS C., LAVEE H., SARAH P. Analysis of soil surface component patterns affecting runoff generation. An example of methods applied to Mediterranean hillslopes in Alicante (Spain). Geomorphology 101, (4), 595, 2008.

15. HAYGARTH P.M., WOOD F.L., HEATHWAITE A.L., BUTLER P.J. Phosphorus dynamics observed through increasing scales in a nested headwater-to-river channel study. Sci. Total Environ. 344, 83, 2005.

16. NAZAHIYAH R., YUSOP Z., ABUSTAN I. Storm water quality and pollution loading from an urban residential catchment in Johor, Malaysia. Water Science \& Technology 56, (7), 1-9, 2007.

17. VORREITER L., HICKEY C. Incidence of the first flush phenomenon in catchments of Sydney region. In:National conference publication-Institution of engineers 3, 359, 1994.

18. MANIQUIZ M.C., LEE S., KIM L.H. Multiple linear regression models of urban runoff pollutant load and event mean concentration considering rainfall variables. Journal of Environmental Sciences 22, (6), 946, 2010.

19. KATO T., KURODA H., NAKASONE H. Runoff characteristics of nutrients from an agricultural watershed with intensive livestock production. J. Hydrol. 368, 79, 2009.

20. ZHU B., WANG T., KUANG F.H., LUO Z.X., TANG J.L., XU T.P. Measurements of nitrate leaching from hillslope cropland in the central Sichuan Basin, China. Soil Science Society of America Journal 73, (4), 1419, 2009.

21. BECHMANN M., DEELSTRA J., STALNACHE P., EGGESTAD H.O., OYGARDEN L., PENGERUD A. Monitoring catchment scale agricultural pollution in Norway: policy instruments, implementation of mitigation methods and trends in nutrient and sediment losses. Environmental Science \& Policy 11, 102, 2008.

22. TANG J L., ZHANG B., GAO C., ZEPP H. Hydrological pathway and source area of nutrient losses identified by a multi-scale monitoring in an agricultural catchment. Catena 72, 374, 2008. 
23. MCKERGOW L.A., WEAVER D.M., PROSSER I.P., GRAYSON R.B., REED A.E.G. Before and after riparian management: sediment and nutrient exports from a small agricultural catchment, Western Australia. J. Hydrol. 270, 253, 2003.

24. PAUL M.J., MEYER J.L. Streams in the urban landscape. Annu. Rev. Ecol. Syst. 32, 333, 2001.

25. BECK M.B. Vulnerability of water quality in intensively developing urban watersheds. Environmental Modelling and Software 20, 379, 2005.

26. KAYE J.P, GROFFMAN P.M, GRIMM N.B, BAKER L.A, POUYAT R.V. A distinct urban biogeochemistry? Trends Ecol. Evol. 21, 192, 2006.
27. ADAMS B.J., and PAPA F. Urban Stormwater Management Planning with Analytical Probabilistic Models, John Wiley and Son, New York, 2000.

28. YUSOP Z., TAN L.W., UJIANG Z., MOHAMED M., NASIR K.A. Runoff quality and pollution loadings from a tropical urban catchment. Water Sci. Technol. 52, (9), 125, 2005.

29. BREZONIK P.L., STADELMANN T.H. Analysis and predictive models of storm water runoff volumes, loads, and pollutant concentrations from watersheds in the Twin Cities metropolitan area, Minnesota, USA. Water Res., 36, 1743, 2002.

30. THOMANN R.V., MUELLER J.A. Principles of surface water quality modeling and control. New York:Harper and Row, 1987. 
